\title{
CT scan structured report for the study of abdominal wall defects: a fast correspondence
}

\author{
P. Sookaromdee ${ }^{1}\left(\mathbb{D} \cdot\right.$ V. Wiwanitkit ${ }^{2}$
}

Received: 27 November 2021 / Accepted: 3 December 2021 / Published online: 18 January 2022

(c) The Author(s), under exclusive licence to Springer-Verlag France SAS, part of Springer Nature 2022

\section{Dear Editor,}

We would like to share ideas on "CT scan structured report for the study of abdominal wall defects: a fast, easy and practical tool at the service of both surgeons and radiologist [1]." Carrara et al. reported that "Our structured report represents a fundamental tool capable of providing the .... all the needed parameters using the same standards"'[1]. We agree that the CT scan structured report is a useful tool. In surgery, a disease-specific structured report is proven more reliable than simple structured report in describing important features required for surgical procedural planning [2]. The present study is based on Delphibased study technique. The content of the tool is based on ideas from groups of experts in a limited area and it is questionable about implementation in other areas. Also, the CT scan report is the last step of investigation. Quality of investigation must include good control of pre-analytical, analytical and post-analytical phases. Finally, to conclude that the tool is fast, it needs a basic study to monitoring exact turnaround comparing use and not use of the new tool.

\section{Declarations}

Conflict of interest The authors declare no conflicts of interest.

Ethical approval Not applicable.

Human and animal rights Not applicable.

Informed consent Not applicable.

\section{References}

1. Carrara A, Nava FL, Costa M, Fabris L, Zuolo M, Pellecchia L, Moscatelli P, Dorna A, Calabrese E, Ferrari M, Paganelli F, Recla M, Tirone G (2021) CT scan structured report for the study of abdominal wall defects: a fast, easy and practical tool at the service of both surgeons and radiologist. Hernia 25(6):1685-1692

2. Franconeri A, Boos J, Fang J, Shenoy-Bhangle A, Perillo M, Wei CJ, Garrett L, Esselen K, Fong L, Brook OR (2019) Adnexal mass staging CT with a disease-specific structured report compared to simple structured report. Eur Radiol 29(9):4851-4860

Publisher's Note Springer Nature remains neutral with regard to jurisdictional claims in published maps and institutional affiliations.

This comment refers to the article available online at https://doi. org/10.1007/s10029-021-02503-8.

\footnotetext{
P. Sookaromdee

pathumsook@gmail.com

Private Academic Consultant, Bangkok, Thailand

2 Dr. DY Patil University, Pune, India
} 